\title{
Porous $\mathrm{Co}_{2} \mathrm{VO}_{4}$ Nanodisk as a High-Energy and Fast-Charging Anode for Lithium-Ion Batteries
}

Cite as

Nano-Micro Lett.

(2022) 14:5

Received: 26 August 2021

Accepted: 22 October 2021

Published online: 2 December 2021

(C) The Author(s) 2021

\author{
Jinghui Ren ${ }^{1}$, Zhenyu Wang ${ }^{2,3}$, Peng Xu ${ }^{1}$, Cong Wang ${ }^{1}$, Fei Gao ${ }^{1}$, Decheng Zhao ${ }^{1}$, \\ Shupei Liu ${ }^{1}$, Han Yang ${ }^{1}$, Di Wang ${ }^{1}$, Chunming $\mathrm{Niu}^{2}$, Yusong Zhu ${ }^{1}$, Yutong Wu${ }^{1}$, \\ Xiang Liu ${ }^{1}$, Zhoulu Wang ${ }^{1}$, Yi Zhang ${ }^{1} \otimes$
}

\section{HIGHLIGHTS}

- The $\mathrm{Li}^{+}$diffusion coefficient of $\mathrm{Co}_{2} \mathrm{VO}_{4}$ is evaluated by theoretical calculation to be as high as $3.15 \times 10^{-10} \mathrm{~cm}^{2} \mathrm{~s}^{-1}$, theoretically proving $\mathrm{Co}_{2} \mathrm{VO}_{4}$ a promising anode in fast-charging lithium-ion batteries.

- A hexagonal porous $\mathrm{Co}_{2} \mathrm{VO}_{4}$ nanodisk (PCVO ND) structure is designed, featuring a high specific surface area of $74.57 \mathrm{~m}^{2} \mathrm{~g}^{-1}$ and numerous pores with a pore size of $14 \mathrm{~nm}$.

- The PCVO ND shows excellent fast-charging performance (a high average capacity of $344.3 \mathrm{mAh} \mathrm{g}^{-1}$ at $10 \mathrm{C}$ for 1000 cycles with only $0.024 \%$ capacity loss per cycle for 1000 cycles).

\begin{abstract}
High-energy-density lithium-ion batteries (LIBs) that can be safely fast-charged are desirable for electric vehicles. However, sub-optimal lithiation potential and low capacity of commonly used LIBs anode cause safety issues and low energy density. Here we hypothesize that a cobalt vanadate oxide, $\mathrm{Co}_{2} \mathrm{VO}_{4}$, can be attractive anode material for fast-charging LIBs due to its high capacity $(\sim 1000$ $\left.\mathrm{mAh}{ }^{-1}\right)$ and safe lithiation potential $\left(\sim 0.65 \mathrm{~V}\right.$ vs. $\left.\mathrm{Li}^{+} / \mathrm{Li}\right)$. The $\mathrm{Li}^{+}$ diffusion coefficient of $\mathrm{Co}_{2} \mathrm{VO}_{4}$ is evaluated by theoretical calculation to be as high as $3.15 \times 10^{-10} \mathrm{~cm}^{2} \mathrm{~s}^{-1}$, proving $\mathrm{Co}_{2} \mathrm{VO}_{4}$ a promising anode in fast-charging LIBs. A hexagonal porous $\mathrm{Co}_{2} \mathrm{VO}_{4}$ nanodisk (PCVO ND) structure is designed accordingly, featuring a high specific surface area of $74.57 \mathrm{~m}^{2} \mathrm{~g}^{-1}$ and numerous pores with a pore size of $14 \mathrm{~nm}$. This unique structure succeeds in enhancing $\mathrm{Li}^{+}$and electron
\end{abstract}

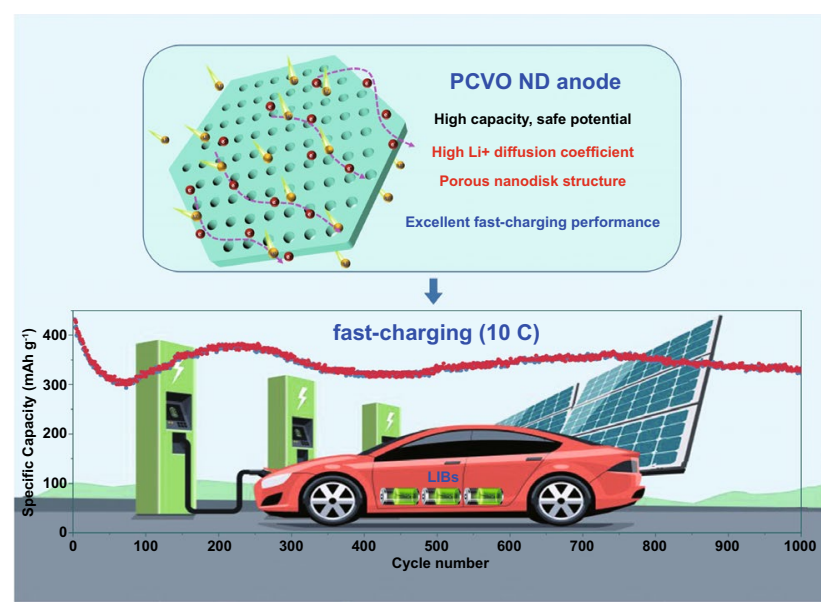
transfer, leading to superior fast-charging performance than current commercial anodes. As a result, the PCVO ND shows a high initial reversible capacity of $911.0 \mathrm{mAh} \mathrm{g}^{-1}$ at $0.4 \mathrm{C}$, excellent fast-charging capacity ( $344.3 \mathrm{mAh} \mathrm{g}^{-1}$ at $10 \mathrm{C}$ for 1000 cycles), outstanding long-term cycling stability (only $0.024 \%$ capacity loss per cycle at $10 \mathrm{C}$ for 1000 cycles), confirming the commercial feasibility of PCVO ND in fast-charging LIBs.

KEYWORDS Lithium-ion batteries; Anode; Fast-charging; High-energy; Cobalt vanadate oxide

Jinghui Ren and Zhengyu Wang author have contributed equally to this work.

$\bowtie$ Yi Zhang, zhangy@njtech.edu.cn

${ }^{1}$ School of Energy Science and Engineering, Nanjing Tech University, Nanjing 211816, People's Republic of China

2 Center of Nanomaterials for Renewable Energy, State Key Laboratory of Electrical Insulation and Power Equipment, School of Electrical Engineering, Xi' an Jiaotong University, Xi' an 710054, People's Republic of China

3 Department of Computational Materials Design, Max-Planck-Insitut Für Eisenforschung GmbH, Max-Planck-Straße 1, 40237 Düsseldorf, Germany 


\section{Introduction}

Lithium-ion batteries (LIBs) are widely used for portable electronic devices in the past decade because of their highenergy density, long cycling life, low self-discharge, the absence of memory effect, and low environmental impact [1, 2]. In recent years, LIBs have aroused extensive attention as the power source for electric vehicles (EVs). At present, EVs have advanced rapidly in terms of both range and cost yet there is still a lack of consumer acceptance and low market penetration of current EVs [3]. The main reason is that the current LIBs in EVs require a long charging time (hours or longer) in a safe manner compare with conventional gasoline vehicles [4]. Thus, improving the fast-charging performance of LIBs is critical to mainstream adoption of EVs for a sustainable future.

As a result, the US Department of Energy has set a goal for designing a LIBs pack that can withstand a 200-mile charge in only $7.5 \mathrm{~min}$ [5]. Achieving this goal requires LIBs' anode materials can be charged to a specific capacity of 175 to $200 \mathrm{mAh} \mathrm{g}^{-1}$ at a current density of $>10 \mathrm{~A} \mathrm{~g}^{-1}$ [6]. Nevertheless, current LIBs commonly used anodes do not meet the requirements. Graphite is the most popular anode material for commercial LIBs because of its high theoretical capacity ( $372 \mathrm{mAh} \mathrm{g}^{-1}$ ), high cycling stability, and low cost $[7,8]$. However, graphite is unsatisfactory in fast-charging LIBs due to its lithiation potential $\left(\sim 0.1 \mathrm{~V} \mathrm{vs.} \mathrm{Li}^{+} / \mathrm{Li}\right)$, which is close to lithium metal's potential $\left(0 \mathrm{~V}\right.$ vs. $\left.\mathrm{Li}^{+} / \mathrm{Li}\right)$ that lithium dendrites can quickly grow while charging at high rates. The lithium dendrites on the surface of the anode can puncture the polymer separator and connect the positive and negative electrodes, causing a short circuit that will lead to fire or explosion [9].

As an alternative, spinel $\mathrm{Li}_{4} \mathrm{Ti}_{5} \mathrm{O}_{12}$, with a high working potential $\left(\sim 1.55 \mathrm{~V}\right.$ vs. $\left.\mathrm{Li}^{+} / \mathrm{Li}\right)$, can be fast-charged without the concern of lithium dendrites growth and safety issues $[10,11]$. Therefore, $\mathrm{Li}_{4} \mathrm{Ti}_{5} \mathrm{O}_{12}$ has been widely studied and already used as an anode for fast-charging LIBs in electric buses. Nevertheless, the energy density of LIBs based on $\mathrm{Li}_{4} \mathrm{Ti}_{5} \mathrm{O}_{12}$ anode is severely limited by the low theoretical capacity of $\mathrm{Li}_{4} \mathrm{Ti}_{5} \mathrm{O}_{12}\left(175 \mathrm{mAh} \mathrm{g}^{-1}\right)$ and high lithiation potential [12]. Besides graphite and $\mathrm{Li}_{4} \mathrm{Ti}_{5} \mathrm{O}_{12}, \mathrm{Si}$ is also a commercially available LIBs anode. Si possesses an ultrahigh theoretical capacity (4200 $\mathrm{mAh} \mathrm{g}^{-1}$ ) and a low, yet safe lithiation potential $\left(\sim 0.22 \mathrm{~V}\right.$ vs. $\left.\mathrm{Li}^{+} / \mathrm{Li}\right)$, holding great promise in safe and high-energy anodes for LIBs $[13,14]$. However, its fast-charging performance deteriorates because of the enormous volume change ( 400\%) and low $\mathrm{Li}^{+}$diffusion coefficient $\left(4.60 \times 10^{-14} \mathrm{~cm}^{2} \mathrm{~s}^{-1}\right)$ during cycling [15]. Thus, it is essential to develop novel anode materials for fastcharging LIBs simultaneously featuring suitable lithiation potential, high capacity, and fast lithium diffusion.

Recently a novel spinel cobalt vanadate oxide $\left(\mathrm{Co}_{2} \mathrm{VO}_{4}\right)$ exhibits several attractive features in LIBs, such as suitable $\mathrm{Li}^{+}$lithiation potential, high capacity, and high electrochemical stability [16]. Through mixed intercalation and conversion reaction mechanism originated from the multiple valence states of $\mathrm{V}$ and Co element, the $\mathrm{Co}_{2} \mathrm{VO}_{4}$ anode can deliver a high stable capacity of $706.8 \mathrm{mAh} \mathrm{g}^{-1}$ at $1.0 \mathrm{~A} \mathrm{~g}^{-1}$ after 1000 cycles with a relatively low, yet safe $\mathrm{Li}^{+}$lithiation potential ( $\sim 0.65 \mathrm{~V}$ vs. $\left.\mathrm{Li}^{+} / \mathrm{Li}\right)$ [17]. Based on these good electrochemical performances, we hypothesize that $\mathrm{Co}_{2} \mathrm{VO}_{4}$ can be an attractive anode material for fast-charging LIBs. We first evaluate the $\mathrm{Li}^{+}$diffusion coefficient of $\mathrm{Co}_{2} \mathrm{VO}_{4}$ by ab initio molecular dynamics (AIMD) calculation which shows the $\mathrm{Li}^{+}$diffusion coefficient of $\mathrm{Co}_{2} \mathrm{VO}_{4}$ is as high as $3.15 \times 10^{-10} \mathrm{~cm}^{2} \mathrm{~s}^{-1}$, proving $\mathrm{Co}_{2} \mathrm{VO}_{4}$ a promising anode in fast-charging LIBs. Then we design a hexagonal porous nanodisk (PCVO ND) structure which can reduce the electron and ion diffusion length, further enhancing the lithium ions and electrons transfer. Moreover, numerous internal pores of PCVO ND can buffer the volume change of PCVO $\mathrm{ND}$, leading to good long-term cycling stability at a high rate (maintain a high stable capacity of $344.3 \mathrm{mAh} \mathrm{g}^{-1}$ at $10 \mathrm{C}$ after 1000 cycles with only $0.024 \%$ capacity loss per cycle). The result demonstrates that PCVO ND is an ideal high-energy fast-charging anode for LIBs.

\section{Materials and Methods}

\subsection{Theoretical Calculation Details}

Our calculations were performed using the plane-wave Vienna Ab initio Simulation Package (VASP) [18-20] within a projector augmented-wave (PAW) pseudo-potential method [21]. The Perdew-Burke-Ernzerhof (PBE) [22] form of GGA exchange-correlation functional was applied. The Hubbard U correction [23] is introduced to describe the effect of localized $d$ electrons of Co and $\mathrm{V}$ ions. The $\mathrm{U}$ value of $\mathrm{Co}$ ions is $5.0 \mathrm{eV}$, while the $\mathrm{U}$ value of $\mathrm{V}$ ions 
is $2.7 \mathrm{eV}$. To study the Li diffusion, ab initio molecular dynamics (AIMD) simulation was carried out under the Born-Oppenheimer approximation. To speed up diffusion and shorten the simulation time scale, AIMD simulations were performed at 500, 750, 1000, 1250, and $1500 \mathrm{~K}$ with a time step of $2 \mathrm{fs}$ after reaching the desired temperature. All these structures were equilibrated for 50 ps before diffusion properties were analyzed. MD simulations in the NVT ensemble with a Nosé-Hoover thermostat [24] were applied. The supercell of $\mathrm{Co}_{2} \mathrm{VO}_{4}$ used for diffusion study comprises $2 \times 2 \times 2$ primitive unit cells ( 16 formula units). $\mathrm{Li}^{+}$are intercalated in the interstitial sites between $\mathrm{CoO}_{6}$ octahedra and $\mathrm{VO}_{4}$ tetrahedra, where each of $\mathrm{Li}^{+}$is surrounded by $6 \mathrm{O}$ ions. $3 \mathrm{Li}^{+}$are intercalated in the 2 formula units of $\mathrm{Co}_{2} \mathrm{VO}_{4}$. A kinetic energy cutoff of $500 \mathrm{eV}$ and a $\Gamma$-centered $1 \times 1 \times 1 \mathrm{k}$-point mesh was adopted to carry out sampling integral for Brillouin zone. These parameters are necessary for convergence of the total energy to within $10^{-5} \mathrm{eV}$ per atom and force less than $0.01 \mathrm{Ev} \AA^{-1}$ per atom.

The diffusion coefficient $(D)$ is defined as the slope of the average mean square displacement (MSD) over $2 d t$ :

$D=\lim _{x \rightarrow \infty} \frac{1}{2 d t} \overline{[\vec{r}(t)]^{2}}$

where $\vec{r}(t)$ is the displacement of the $i$-th lithium ion at time $t$.

The average mean square displacement (MSD) is defined as a measure of the deviation of the position of a particle with respect to a reference position over time:

$\overline{[\vec{r}(t)]^{2}}=\frac{1}{N} \sum_{N}^{i=1} \overline{\left[\vec{r}\left(t+t_{0}\right)\right]^{2}-\left[\vec{r}\left(t_{0}\right)\right]^{2}}$

where $N$ is the total number of $\mathrm{Li}^{+}$in the system.

\subsection{Materials Synthesis}

The hexagonal porous $\mathrm{Co}_{2} \mathrm{VO}_{4}$ nanodisk (PCVO ND) was synthesized by a simple, low cost and scalable route. First, $0.94 \mathrm{~g} \mathrm{NH}_{4} \mathrm{VO}_{3}$ (AR, Aladdin) and $0.46 \mathrm{~g} \mathrm{Co}\left(\mathrm{NO}_{3}\right)_{2} \cdot 6 \mathrm{H}_{2} \mathrm{O}$ (AR, Aladdin) were dissolved in a mixed solvent containing $140 \mathrm{~mL}$ deionized water and $20 \mathrm{~mL}$ ethylene glycol at $80^{\circ} \mathrm{C}$ under vigorous stirring to form a homogeneous solution. Then, 2.8 g C $_{6} \mathrm{H}_{12} \mathrm{~N}_{4}$ (HMT) (AR, Aladdin) was added to the above solution under stirring for $4 \mathrm{~h}$. With the assistance of HMT, the larger crystal nucleus continuously absorbs the mass produced by the dissolution of the smaller crystal nucleus and then grows, which is caused by the descend of interface energy of the total surface of the particle phase [25]. Next, the solution was filtrated and washed several times with deionized water and ethanol to collect a precipitate. The precipitate Cwas dried in an oven at $80{ }^{\circ} \mathrm{C}$ for $12 \mathrm{~h}$ to obtain the precursor. Finally, the $\mathrm{Co}_{2} \mathrm{VO}_{4}$ precursor was calcined in a tubular furnace at $350{ }^{\circ} \mathrm{C}$ for $4 \mathrm{~h}$ under $\mathrm{Ar} / \mathrm{H}_{2}$ (90\%/10\%) atmosphere, which mainly removed water in the precursor to form the porous $\mathrm{Co}_{2} \mathrm{VO}_{4}$ nanodisk. The Schematic illustration of PCVO ND synthesis is shown in Fig. 1.

\subsection{Characterization}

The crystalline characteristic of as-prepared samples was identified by X-ray diffractometer (XRD, Rigaku MiniFlexll) with $\mathrm{Cu} \mathrm{K} \alpha$ radiation $(\lambda=0.15406 \mathrm{~nm})$ at a scanning angle (20) range of $10^{\circ}$ to $90^{\circ}$. X-ray photoelectron spectra (XPS, Thermo Scientific K-Alpha) measurements were performed using an Al K $\alpha \mathrm{X}$-ray source. Nitrogen adsorption-desorption isotherms were conducted by a Quantachrome instruments Autosorb-IQ3 system. The morphology and surface details of PCVO ND were analyzed by scanning electron microscopy (SEM, JEOL JSM-7800F Field Emission) and transmission electron microscopy (TEM, JEOL JEM, 1011).

\subsection{Electrochemical Measurements}

The electrodes were prepared by mixing $70 \mathrm{wt} . \%$ active material (PCVO ND or graphite or $\mathrm{Li}_{4} \mathrm{Ti}_{5} \mathrm{O}_{12}$ or $\mathrm{Si}$ ), 20 wt.\% acetylene black, and $10 \mathrm{wt} . \%$ polyvinylidene fluoride (PVDF) in N-methylpyrrolidinone (NMP) to form a slurry. The slurry was cast on copper foil and dried in a vacuum oven at $80{ }^{\circ} \mathrm{C}$ for $12 \mathrm{~h}$. The active material mass loading on each electrode for graphite, $\mathrm{Li}_{4} \mathrm{Ti}_{5} \mathrm{O}_{12}, \mathrm{Si}$, and PCVO $\mathrm{ND}$ is around $0.6 \mathrm{mg} \mathrm{cm}^{-2}$. The CR2025 coin-type half cells were assembled in an Ar-filled glovebox using the as-prepared electrode as the working electrode, lithium foil as the counter electrode, and a Cellgard 2400 microporous membrane as the separator. $1 \mathrm{M} \mathrm{LiPF}_{6}$ dissolved in ethylene carbonate (EC) and dimethyl carbonate (DEC) (1:1, in volume) with $5 \mathrm{wt}$ \% fluoroethylene carbonate (FEC) was used as the electrolyte. The GITT test was carried out on a LAND battery-test instrument (CT2001A) to obtain the $\mathrm{Li}^{+}$diffusion coefficient of PCVO ND. Cyclic 
voltammetry $(\mathrm{CV})$ curves between $0 \mathrm{~V}$ and $3.0 \mathrm{~V}$ with a scan rate of $0.2 \mathrm{mV} \mathrm{s}^{-1}$ were tested by an electrochemical workstation (CHI-660D). Electrochemical impedance spectroscopy (EIS) curves were recorded by CHI-660D electrochemical workstation, and the frequency range is $100 \mathrm{kHz}$ to $0.01 \mathrm{~Hz}$. The fast-charging performance of PCVO ND was measured at $4 \mathrm{C}$ and $10 \mathrm{C}$ using a LANDCT2001A system $\left(1 \mathrm{C}=1000 \mathrm{~mA} \mathrm{~g}^{-1}\right)$. For comparison, graphite, $\mathrm{Li}_{4} \mathrm{Ti}_{5} \mathrm{O}_{12}$, $\mathrm{Si}$ was also measured at $400 \mathrm{~mA} \mathrm{~g}^{-1}$ and $4000 \mathrm{~mA} \mathrm{~g}^{-1}$. Besides, the lithium-ion full cell was assembled using $\mathrm{LiCoO}_{2}$ and PCVO ND as cathode and anode, respectively. The cathode was fabricated by mixing 70 wt. $\% \mathrm{LiCoO}_{2}, 20 \mathrm{wt} . \%$ acetylene black, and $10 \mathrm{wt} . \%$ PVDF in NMP to construct slurry and then spread on Al foil. The PCVO ND was first pre-activated in a half cell to form a stable solid electrolyte interface (SEI) layer and then taken out as anodes for the LIB full cell. The electrolyte and separator in the full cell were identical to those in a half cell.

\section{Results and Discussion}

\subsection{Theoretical Calculations}

To design fast-charging high-energy-density LIBs, high capacity, fast lithium diffusion, suitable working potential, and high cycling stability are four essential parameters for electrode materials. $\mathrm{Co}_{2} \mathrm{VO} 4$ exhibits several advantages in high-energy-density LIBs, such as high capacity ( $1000 \mathrm{mAh}$ g-1), relatively low yet safe lithiation potential $\left(\sim 0.65 \mathrm{~V}\right.$ vs. $\left.\mathrm{Li}^{+} / \mathrm{Li}\right)$, and excellent electrochemical stability [16]. Thus, we hypothesized that $\mathrm{Co}_{2} \mathrm{VO}_{4}$ could be an attractive fast-charging anode material for LIBs. To prove it, we first calculated the $\mathrm{Li}^{+}$diffusion coefficient $\left(D_{\mathrm{Li}}\right)$ of $\mathrm{Co}_{2} \mathrm{VO}_{4}$ for all paths found by the AIMD simulations. The $D_{\mathrm{Li}}$ was calculated based on the averaged mean square displacement of $\mathrm{Li}$ ions over time. Convergence of $D_{\mathrm{Li}}$ was achieved by MD simulations of $50 \mathrm{ps}$ approximately. The Arrhenius plot for the variety of $D_{\mathrm{Li}}$ at temperatures from 500 to $1500 \mathrm{~K}$ is shown in Fig. 2a. The extrapolated $D_{\mathrm{Li}}$ at $300 \mathrm{~K}$ was $3.15 \times 10^{-10} \mathrm{~cm}^{2} \mathrm{~s}^{-1}$ which was $1 \sim 6$ orders of magnitude higher than that of commercial graphite $\left(4.0 \times 10^{-11} \mathrm{~cm}^{2} \mathrm{~s}^{-1}\right)$ [26], $\mathrm{Li}_{4} \mathrm{Ti}_{5} \mathrm{O}_{12}\left(1.0 \times 10^{-15} \mathrm{~cm}^{2} \mathrm{~s}^{-1}\right)$ [27], and $\mathrm{Si}\left(4.60 \times 10^{-14} \mathrm{~cm}^{2} \mathrm{~s}^{-1}\right)$ [15], theoretically proving $\mathrm{Co}_{2} \mathrm{VO}_{4}$ a promising anode material for fast-charging LIBs. The trajectory of $\mathrm{Li}^{+}$diffusion was described by its time-averaged spatial occupancy probability in the crystal structure, of which top view and side view is displayed in Fig. 2b, d. The probability densities of $\mathrm{Li}$ ions were localized in the space between pairs of point-sharing $\mathrm{CoO}_{6}$ octahedra and $\mathrm{VO}_{4}$ tetrahedra. Migration could occur via the channels connecting octahedrally coordinated interstitial sites along subdiagonal of $a, b$, or $c$ axes, where each of interstitial site is surrounded by $6 \mathrm{O}$ ions.

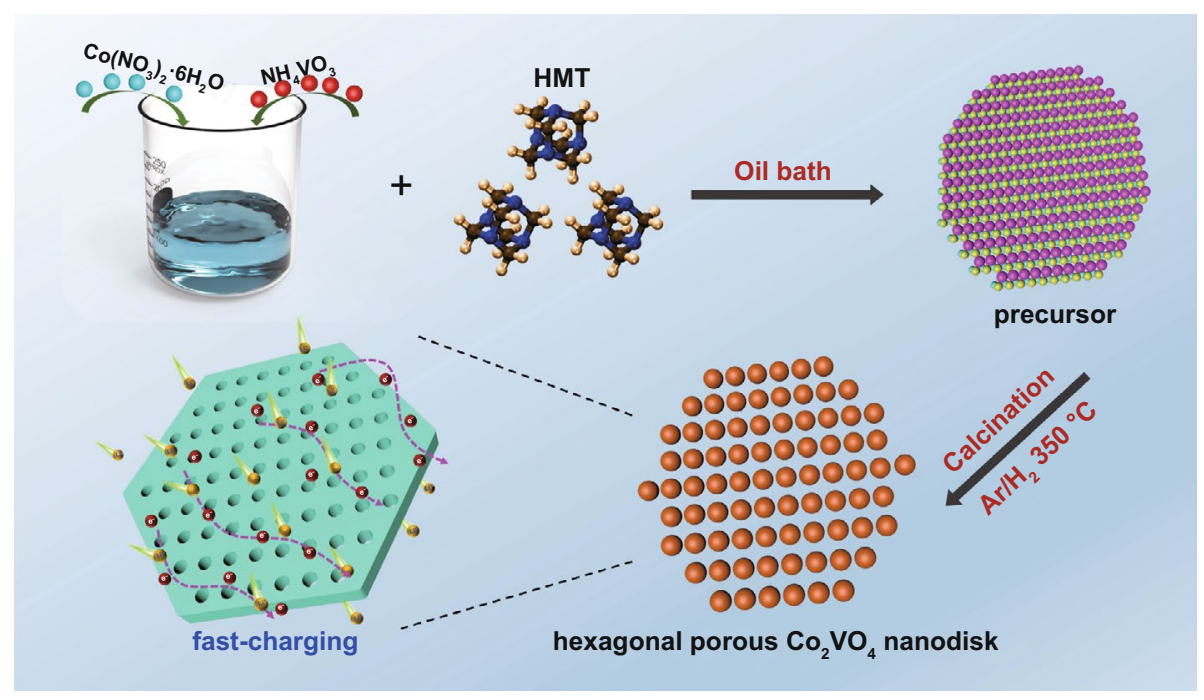

Fig. 1 Schematic illustration of PCVO ND synthesis 
Besides the inherent property of anode materials, material structure design is also important for achieving good fast-charging performance. The porous nanodisk structural design can reduce the electron and ion diffusion length at the electrode level, further accelerating the electrochemical reactions. Thus, we designed a hexagonal porous $\mathrm{Co}_{2} \mathrm{VO}_{4}$ nanodisk (PCVO ND) structure and then investigated $D_{\mathrm{Li}}$ of our PCVO ND experimentally by galvanostatic intermittent titration technique (GITT) with a pulse current density of $100 \mathrm{~mA} \mathrm{~g}^{-1}$ for $10 \mathrm{~min}$ between $20 \mathrm{~min}$ rest intervals (Fig. 2c). The $D_{\mathrm{Li}}$ can be calculated by the following equation [27]:
$D=\frac{4 L^{2}}{\pi \tau}\left(\frac{\Delta E_{S}}{\Delta E_{t}}\right)^{2}$

where $L$ is lithium-ion diffusion length, $t$ is the duration of the current pulse, and $\tau, \Delta E_{S}$, and $\Delta E_{t}$ are the galvanic titration, voltage change between steps, and voltage change during the pulse period, respectively. Based on GITT measurement and Eq. (3), the average $D_{\mathrm{Li}}$ of PCVO was $6.95 \times 10^{-10}$ $\mathrm{cm}^{2} \mathrm{~s}^{-1}$, showing the same order of magnitude that AIMD simulations have achieved. The $D_{\mathrm{Li}}$ of our PCVO ND was higher than that of commercial anode materials (graphite, $\mathrm{Li}_{4} \mathrm{Ti}_{5} \mathrm{O}_{12}$, and $\mathrm{Si}$ ) and higher than that of previously reported fast-charging anode materials [28-32] (Fig. 2e), (a)

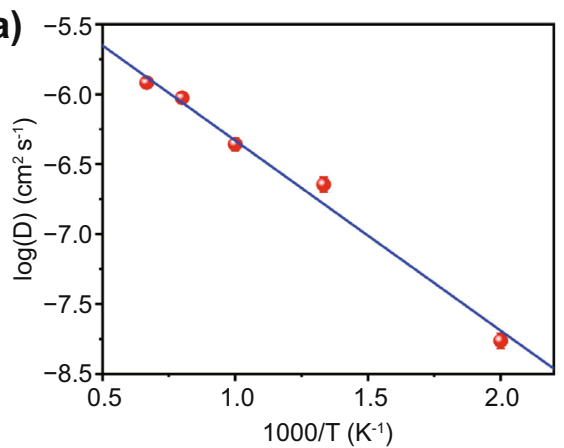

(c)

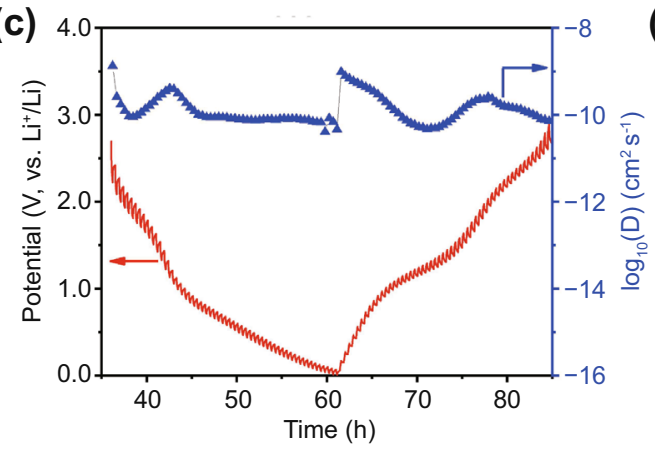

(b)

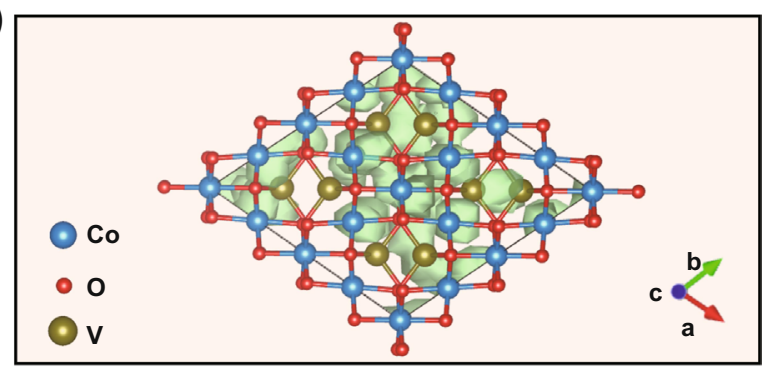

(d)

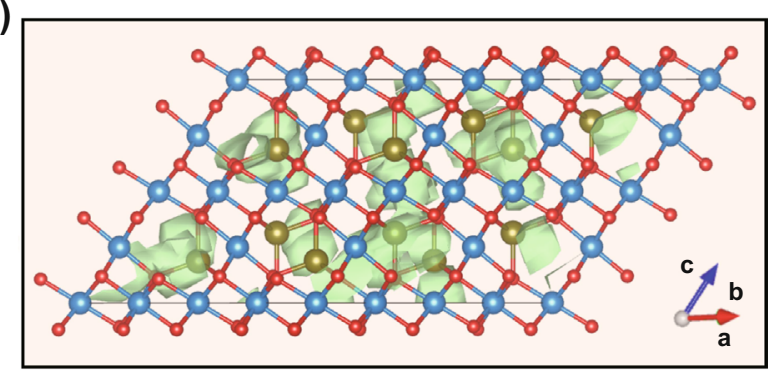

(e)

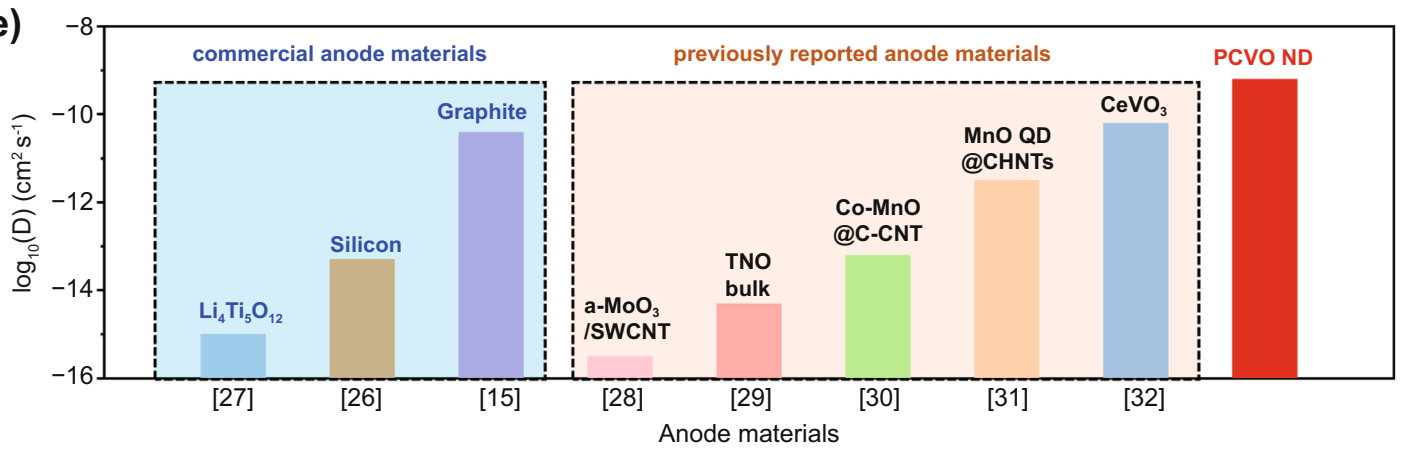

Fig. 2 a Arrhenius plot of overall diffusion coefficient, where the error bar corresponds to statistical uncertainty in the fitting of the mean square displacement to time curve. $\mathbf{b}$ Top view and $\mathbf{d}$ side view of isosurfaces of lithium ion probability density during an AIMD simulation. $\mathbf{c}$ GITT curve and corresponding $\mathrm{Li}^{+}$diffusion coefficient of PCVO ND. e The comparison of $\mathrm{Li}^{+}$diffusion coefficient of PCVO ND with commercial anode materials and other previously reported anode materials 
experimentally confirming PCVO ND's feasibility in fastcharging high-energy-density LIBs. These detailed $D_{\mathrm{Li}}$ are summarized in Table S1.

\subsection{Structure and Morphology of PCVO ND}

Figure 3a shows the XRD pattern of PCVO ND. The diffraction peaks at $2 \theta$ of $30.1^{\circ}, 35.5^{\circ}, 37.1^{\circ}, 43.1^{\circ}, 47.2^{\circ}$, $53.5^{\circ}, 57.0^{\circ}$, and $62.6^{\circ}$ were indexed to the (220), (311), (222), (400), (331), (422), (511), and (440) diffraction planes of spinel $\mathrm{Co}_{2} \mathrm{VO}_{4}$ (JCPDS No.73-1633) [33], indicating PCVO ND has high crystallinity. PCVO ND's facecentered cubic spinel structure was displayed in Fig. S1a, composing of Fd-3 m space group and cubic cells. Both Co and $\mathrm{V}$ atoms occupy the tetrahedral and octahedral crystallographic sites in the crystal structure of $\mathrm{Co}_{2} \mathrm{VO}_{4}$. The two adjacent octahedral sites were formed as a chain by sharing their two oxygen edge-shared corners. The solitary octahedral sites in two different chains were connected to the two separate tetrahedral sites by cross-linking their individual oxygen corners to complete the entire cubic structure. The stable crystal structure was beneficial to improve cycling stability. To investigate PCVO ND's chemical information, XPS measurement was carried out and the result is shown in Fig. 3b. The Co, V, and O elements can be clearly indicated in the full survey spectrum of PCVO ND. Figure $\mathrm{S} 1 \mathrm{~b}$ shows the Co $2 \mathrm{p}$ spectra in which two intense peaks at $780.1 \mathrm{eV}$ and $796.5 \mathrm{eV}$ can be assigned to $\mathrm{Co}^{2+}$ [35]. Figure S1c displays the high-resolution spectra of $\mathrm{V} 2 \mathrm{p}$ in which two peaks at $516.4 \mathrm{eV}$ and $523.7 \mathrm{eV}$ originated from $\mathrm{V} 2 \mathrm{p}_{3 / 2}$ and $\mathrm{V} 2 \mathrm{p}_{1 / 2}$, respectively. The two peaks were ascribed to $\mathrm{V}^{4+}[36]$. The $\mathrm{O} 1 \mathrm{~s}$ signal could be fitted into three oxygen components around 529.9, 530.8, and $531.85 \mathrm{eV}$ (Fig. S1d), which were attributed to the metal-oxygen bonds (M-O), hydroxyl species of surface adsorbed water molecule (M-OH), and oxygen ions in low coordination $\left(\mathrm{O}_{\mathrm{L}}\right)$, respectively $[35,36]$.

The Brunner-Emmet-Teller (BET) and Barrett-JoynerHalenda (BJH) methods were used to study the porous structure of the synthesized PCVO ND, and the results are shown in Fig. 3c. From Fig. 3c, the nitrogen adsorption-desorption isotherm of PCVO ND matched to a typical type IV curve [37], confirming PCVO ND mesoporous structure. And the H3 type hysteresis indicated PCVO ND disk-like structure. The BET specific surface area of PCVO ND was $74.57 \mathrm{~m}^{2} \mathrm{~g}^{-1}$, much higher than that of other cobalt vanadates (Table S2). The large specific surface area of PCVO ND is beneficial to contact between electrode and electrolyte and can provide more reactive sites, promoting the electrode reaction kinetics. And the $\mathrm{BJH}$ analysis revealed that $\mathrm{PCVO}$ ND presented a uniform and small pore size of $14.06 \mathrm{~nm}$ among our PCVO ND sample. The numerous mesopores in PCVO ND shorten the transmission distance of $\mathrm{Li}^{+}$, improving the kinetics of the electrode reaction. Moreover, the porous structure provides a certain space to alleviate the volume expansion problem of PCVO ND during the cycling, prolonging the electrode's cycle life.

The morphology, structure, and element distribution of PCVO ND were characterized by SEM and TEM. Figures $3 \mathrm{~d}$ and $\mathrm{S} 2 \mathrm{a}$ show the low-magnification SEM images of hexagonal $\mathrm{Co}_{2} \mathrm{VO}_{4}$ nanodisk with a width of $\sim 0.15 \mu \mathrm{m}$ and thickness of $\sim 150 \mathrm{~nm}$. The high magnification SEM image (Fig. S2b) revealed a rough surface of PCVO ND in which many pores exist, providing more reactive sites for active substances. Furthermore, the TEM images (Fig. 3e, f) confirmed the nanodisk morphology and mesoporous structure of PCVO ND. The purple round areas presented pores in PCVO ND (Fig. 3f) and the mesopore size was about $15 \mathrm{~nm}$, in agreement with BET results. High-resolution TEM image of PCVO ND (Fig. 3g) revealed a regular atomic arrangement and lattice spacing of $0.252 \mathrm{~nm}$, corresponding to the crystal planes of (311) of spinel $\mathrm{Co}_{2} \mathrm{VO}_{4}$ [33]. The selected area electron diffraction (SAED) (Fig. 3h) showed welldefined diffraction spots with hexagonal symmetry, indicating the polycrystalline nature of $\mathrm{Co}_{2} \mathrm{VO}_{4}$. Figure $3 \mathrm{i}$ showed a low-magnification high-angle annular darkfield (HAADF) STEM image of PCVO ND and corresponding element mapping. Energy-dispersive spectroscopy (EDS) mapping images revealed that PCVO ND was composed of $\mathrm{Co}, \mathrm{V}$, and $\mathrm{O}$ elements, which were homogeneously distributed in the nanodisk. According to the EDS pattern (Fig. S3), the mass fractions of $\mathrm{Co}, \mathrm{V}$, and $\mathrm{O}$ atoms were $49.72 \mathrm{wt} \%, 21.93 \mathrm{wt} . \%$, and 28.35 wt.\%, respectively. By calculating based on relative atomic mass, PCVO ND exhibited the mole ratio of $\mathrm{Co} / \mathrm{V} / \mathrm{O}$ was $1.96: 1: 4.12$, close to the stoichiometry of $\mathrm{Co}_{2} \mathrm{VO}_{4}$. These results demonstrated that the porous $\mathrm{Co}_{2} \mathrm{VO}_{4}$ nanodisk was successfully synthesized. 
(a)
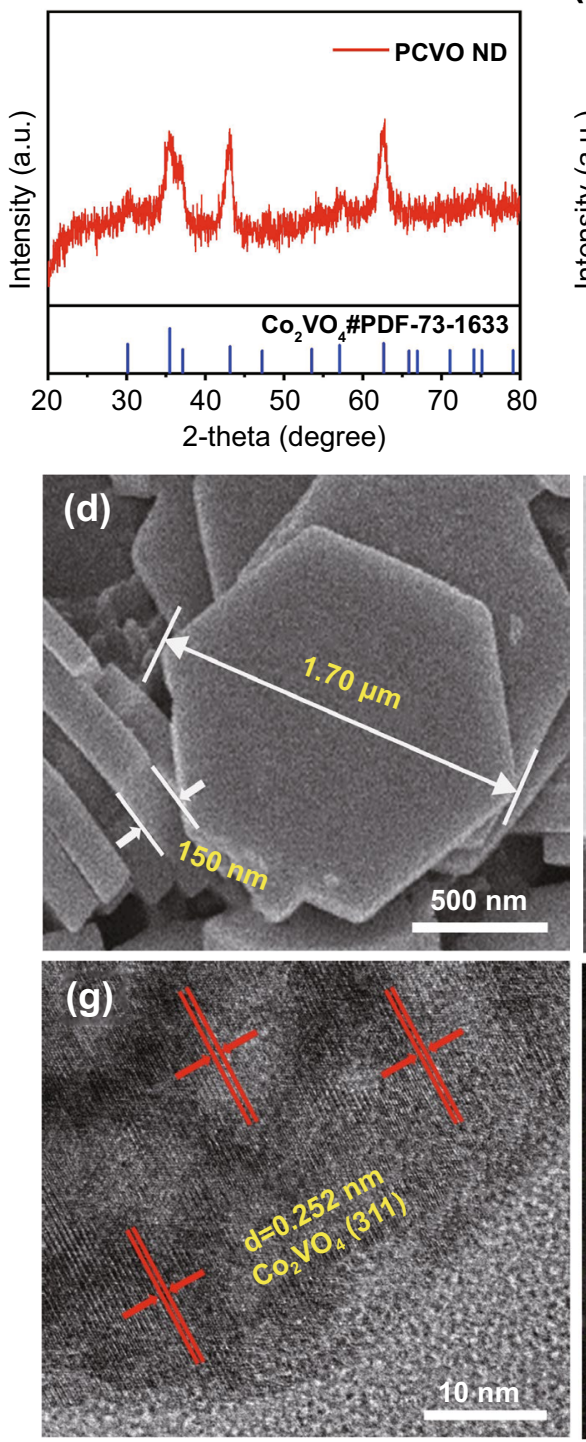

(b)
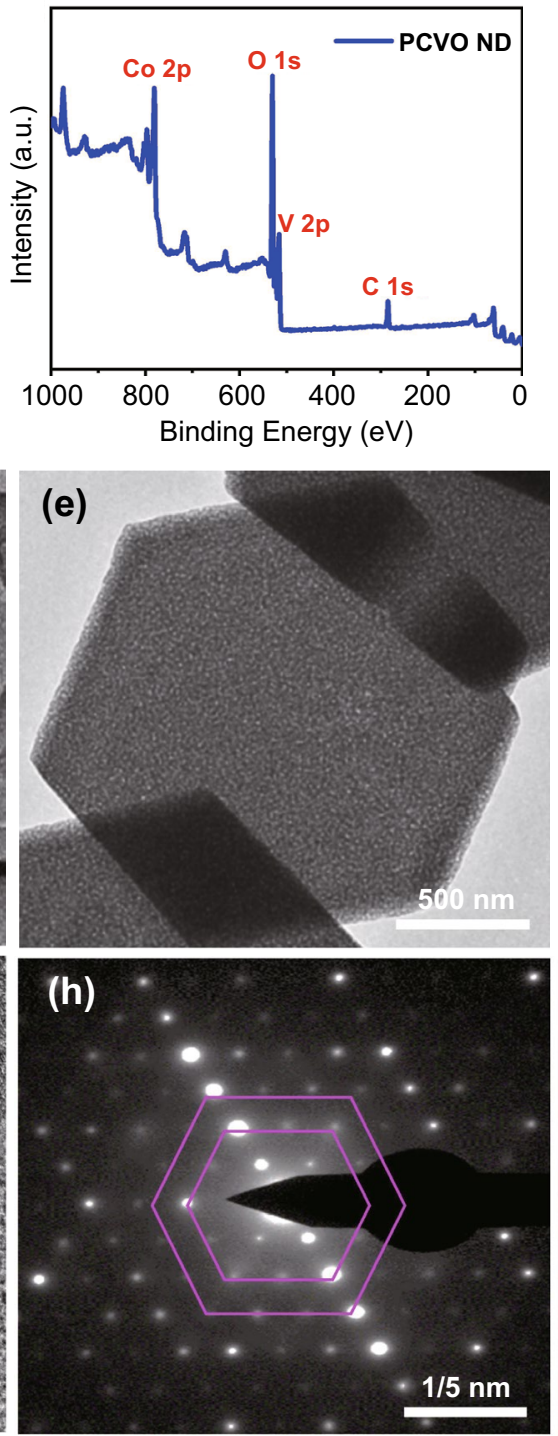

(c)
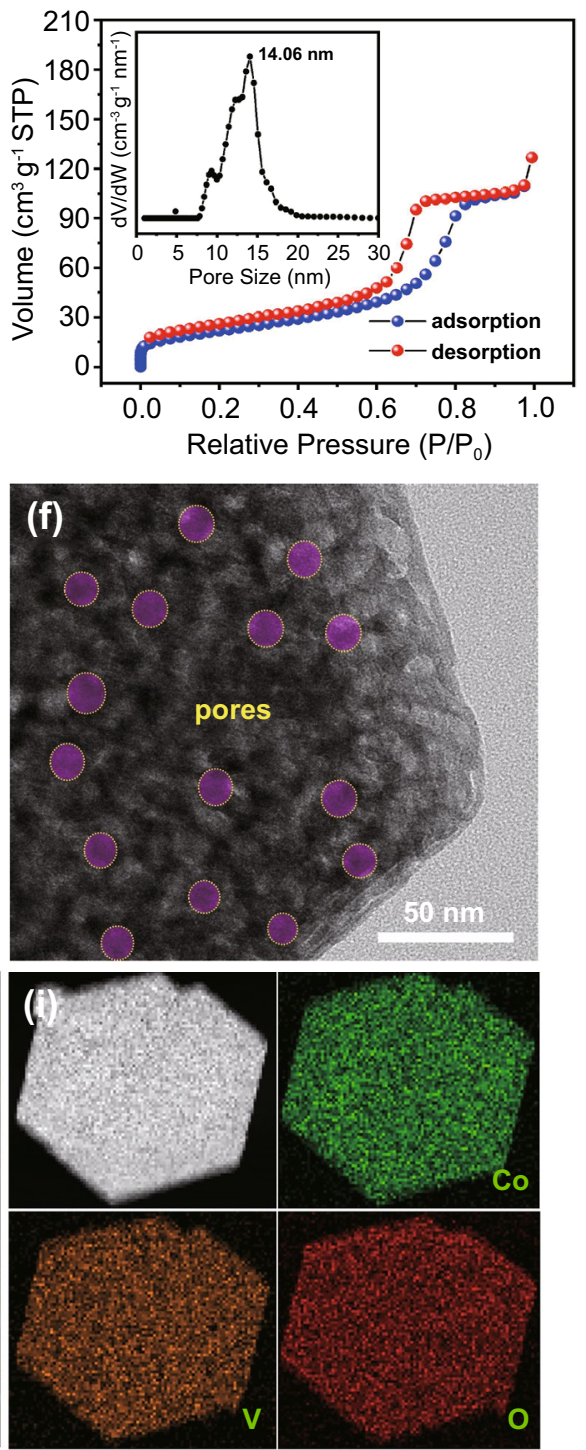

Fig. 3 a XRD pattern of PCVO ND. b XPS full survey spectrum of PCVO ND. c Nitrogen adsorption and desorption isotherms of PCVO ND (Inset is the corresponding pore size distributions). $\mathbf{d}$ FESEM image of PCVO ND. e and $\mathbf{f}$ TEM images. $\mathbf{g}$ HRTEM image. $\mathbf{h}$ SAED pattern. $\mathbf{i}$ STEM and the corresponding elemental mapping images indicating the homogeneous distribution of all three elements of $\mathrm{Co}$, V and $\mathrm{O}$

\subsection{Electrochemical Properties of PCVO ND}

Cyclic voltammetry (CV) was measured to evaluate the lithium storage mechanism of PCVO ND. The initial three CV curves of PCVO ND measured at a scan rate of $0.2 \mathrm{mV} \mathrm{s}^{-1}$ between 0 and $3 \mathrm{~V}\left(\mathrm{vs} . \mathrm{Li}^{+} / \mathrm{Li}\right)$ are shown in Fig. 4a. It can be found that the cathodic behavior of the first cycle was different from that of subsequent cycles. The first cycle only showed two cathodic peaks around 0.06 and $0.34 \mathrm{~V}$. The cathodic peak around $0.06 \mathrm{~V}$ corresponded to the formation of SEI film and the peak at $0.34 \mathrm{~V}$ was related to the transformation from $\mathrm{Co}_{2} \mathrm{VO}_{4}$ to $\mathrm{CoO}$ and $\mathrm{Li}_{\mathrm{x}} \mathrm{VO}_{2}$, as shown in reaction Eq. (4) [17]. These peaks disappeared in the subsequent cycles because the formation of SEI had been complicated and the transformation in reaction Eq. (4) only occurred in the first cycle. In subsequent cycles, two new cathodic peaks at 1.64 and $0.58 \mathrm{~V}$ appeared, corresponding to the transformation from $\mathrm{CoO}$ to $\mathrm{Co}, \mathrm{Li}_{2} \mathrm{O}$ and the intertcalation of $\mathrm{Li}^{+}$into $\mathrm{Li}_{\mathrm{x}} \mathrm{VO}_{2}$, as shown in reaction Eq. (5) [17]. In the delithiation process, PCVO ND showed two oxidation 
peaks at 1.32 and $2.36 \mathrm{~V}$ due to the oxidzation of $\mathrm{Co}$ and the extraction of $\mathrm{Li}^{+}$from $\mathrm{Li}_{x+y} \mathrm{VO}_{2}$. The $\mathrm{CV}$ cures overlapped well, apart from the first cycle, manifesting the remarkable stability of PCVO ND.

$\mathrm{Co}_{2} \mathrm{VO}_{4}+x \mathrm{Li}^{+}+x e^{-} \rightarrow 2 \mathrm{CoO}+\mathrm{Li}_{x} \mathrm{VO}_{2}$

$\mathrm{CoO}+\mathrm{Li}_{x} \mathrm{VO}_{2}+(y+2) \mathrm{Li}^{+}+(y+2) e^{-} \leftrightarrow \mathrm{Co}+\mathrm{Li}_{2} \mathrm{O}+\mathrm{Li}_{x+y} \mathrm{VO}_{2}$

The PCVO ND was measured at $0.4 \mathrm{C}$ within the voltage range of 0.01-3.0 V (vs. $\mathrm{Li}^{+} / \mathrm{Li}$ ). Figure $4 \mathrm{~b}$ displays PCVO ND's galvanostatic discharge-charge curves of the 1st, 2nd, 3rd, 10th, 50th, and 100th. Each discharge curve existed discharge platform in $0.65 \mathrm{~V}$, consistent with $\mathrm{CV}$ results. The 2nd, 3rd, 10th, 50th, and 100th discharge and charge voltage curves almost overlap, revealing high reversibility. The discharge and charge capacity in the first cycle were 1227.0 and $944.1 \mathrm{mAh} \mathrm{g}^{-1}$, with an initial coulombic efficiency of $76.9 \%$. The high discharge capacity in the first cycle is due to the formation of the SEI film. Figure S4 shows the cycling performance of PCVO ND at $0.4 \mathrm{C}$. PCVO ND displayed a high initial reversible capacity of $911.0 \mathrm{mAh} \mathrm{g}^{-1}$. The capacity showed a slight decrease before the 50th cycle and then increased slightly in the subsequent cycles. The capacity was recovered to $817.9 \mathrm{mAh} \mathrm{g}^{-1}$ after 100 cycles, corresponding to a high capacity retention of $89.8 \%$, suggesting high
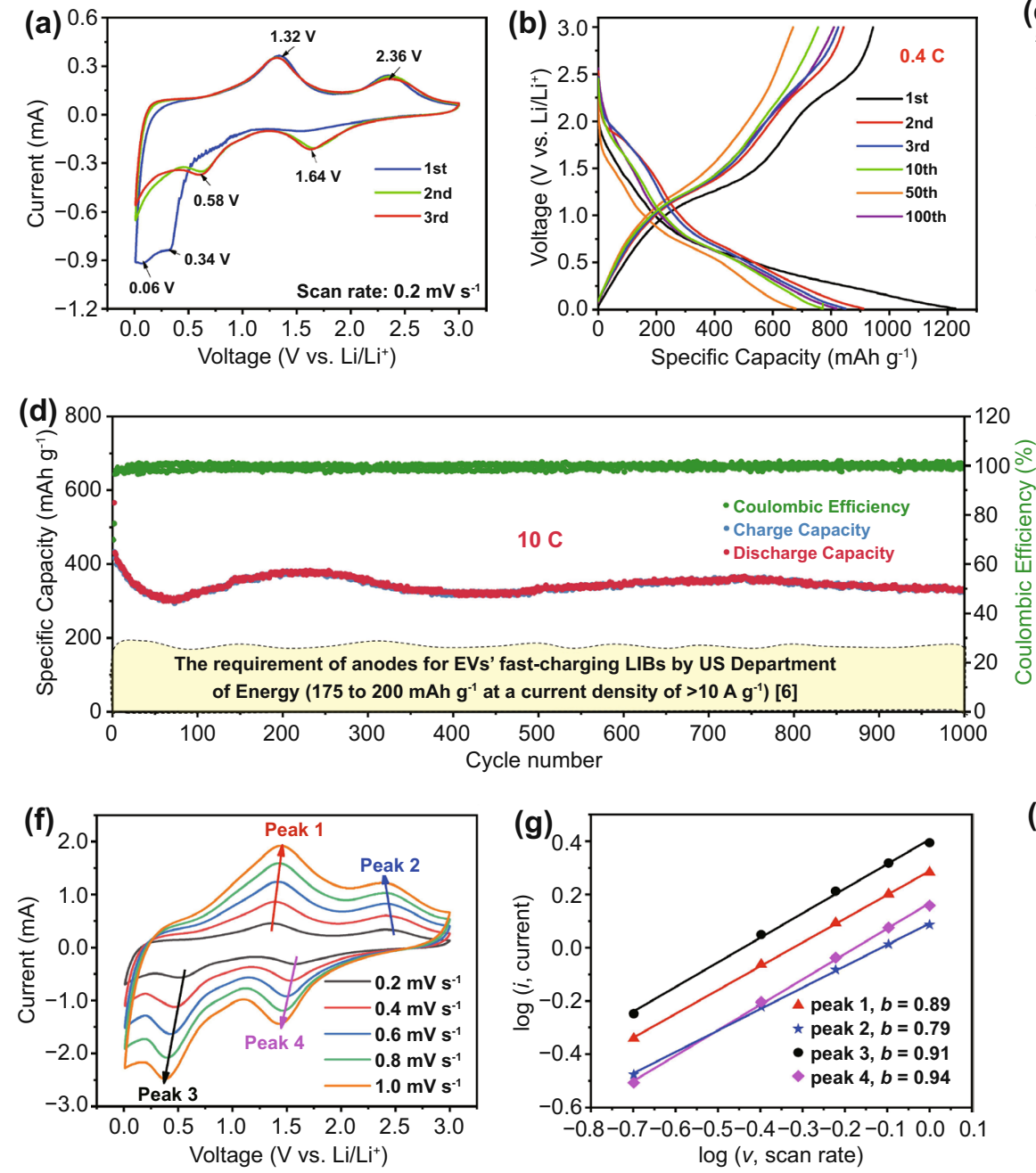
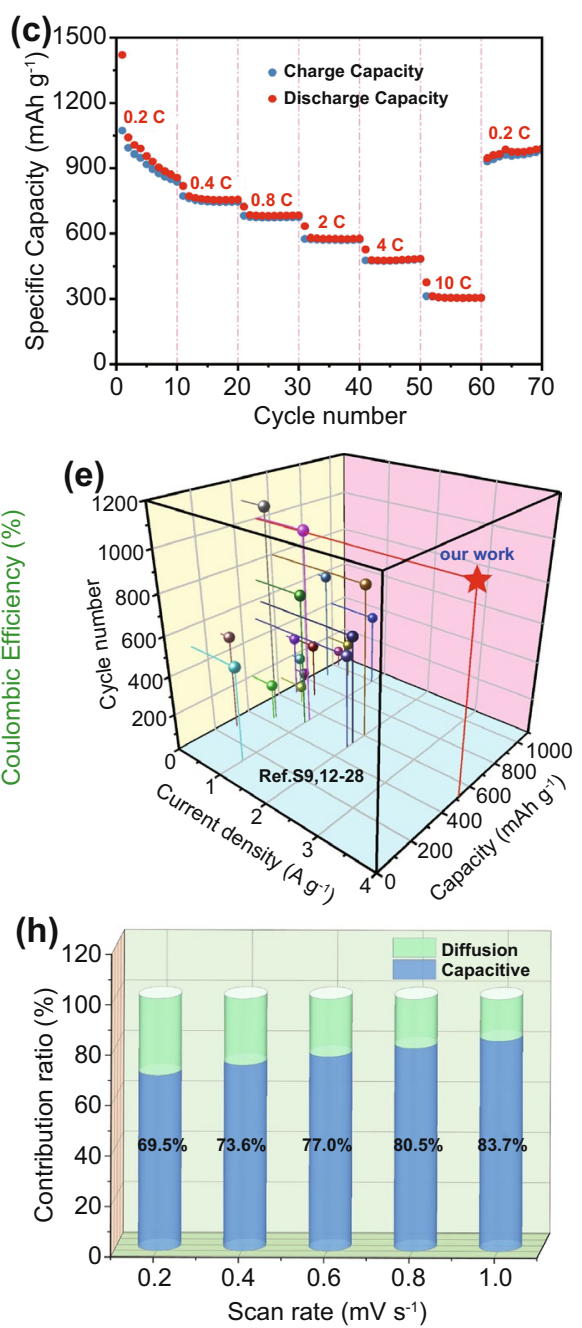

Fig. 4 Electrochemical properties of PCVO ND. a CV curves. b Galvanostatic discharge and charge curves at 0.4 C. c Rate performance. d Cycling performance at $10 \mathrm{C}$. e A comparison of electrochemical properties. $\mathbf{f} \mathrm{CV}$ curves at different scan rates. $\mathbf{g} \log (i) \operatorname{versus} \log (v)$ plots at specific peaks. $\mathbf{h}$ Contribution ratio of the capacitive and diffusion-controlled capacities at various scan rates $\left(1 \mathrm{C}=1000 \mathrm{~mA} \mathrm{~g} \mathrm{~g}^{-1}\right)$ 
cycling stability. Similar results have also been reported for the electrochemical performance of transition metal oxides in the literature $[38,39]$, which may be due to the continuous activation and improvement of $\mathrm{Li}^{+}$ion accessibility with cycling. The exceptional electrochemical performance of PCVO ND electrode at $0.4 \mathrm{C}$ was verified by electrochemical impedance spectroscopy (EIS) test. Figure S5a, b showed Nyquist plots and equivalent circuit model of PCVO ND electrode before cycling and after 1, 10, 50, and 100 cycles. $\mathrm{R}_{1}$ and $\mathrm{R}_{2}$ represent internal resistance, including electrolyte resistance, the internal resistance of active material, and contact resistance between the current collector and active material, while $\mathrm{R}_{3}$ represents the charge transfer resistance. The internal resistance of the PCVO ND electrode before cycling is much larger than that for the following cycles, mainly due to the much-enhanced ion and electron transfer in the electrode. Subsequently, there was little change in the impedance of the PCVO ND electrode, indicating low transfer resistance and good stability of PCVO ND.

Above good electrochemical performances (suitable lithiation potential, high capacity, high cycling stability) along with high $\mathrm{Li}^{+}$diffusion coefficient from both theoretical and experimental results in Fig. 2a, c indicated that PCVO ND has excellent potential in fast-charging LIBs. Thus PCVO ND was tested at high rates. Increasing the rate from 0.2, 0.4, 0.8, 2, 4 to $10 \mathrm{C}$ (Fig. 4c), PCVO ND anode delivered average specific discharge capacities of 857.7, 755.5, 684.6, $575.9,485.3$, and $305.2 \mathrm{mAh} \mathrm{g}^{-1}$, respectively. Meanwhile, returning the rate from 10 to $0.2 \mathrm{C}$, PCVO ND anode's specific discharge capacity recovered to $1021.3 \mathrm{mAh} \mathrm{g}^{-1}$, exhibiting good rate performance and excellent reversibility. The high fast-charging capability of anodes after long-term cycles is of practical importance for applications in EVs. Thus PCVO ND was further tested at $10 \mathrm{C}$ for 1000 cycles (Fig. 4d). Notably, the capacity decreased during the first 70 cycles and gradually increased in the subsequent cycles. This phenomenon was observed in many transition oxides. The rapid capacity decrease is resulted from the conversion reactions, generated volume expansion and formation of SEI layer [16, 25, 34, 42]. The subsequent capacity increase might be attributed to the increased crystallinity of active materials and gradual activation progress during the cycle $[17,36,38]$. Figure $4 d$ showed that PCVO ND exhibited excellent fast-charging capacity (a high average capacity of $344.3 \mathrm{mAh} \mathrm{g}^{-1}$ at $10 \mathrm{C}$ for 1000 cycles) and outstanding long-term cycling stability (only $0.024 \%$ capacity loss per cycle at $10 \mathrm{C}$ for 1000 cycles). A LIB with such PCVO ND anode can be fully charged within $5 \mathrm{~min}$. Thus our PCVO ND met the requirement of anodes for fast-charging LIBs in EVs by the US Department of Energy and showed better fast-charging performance than previously reported fastcharging anodes, summarized in Fig. 4e and Table S3. Such excellent fast-charging performance could be attributed to the following reasons: (i) The various valence states of $\mathrm{V}$ and Co element and the combined intercalation and conversion reaction mechanism lead to a high theoretical capacity; (ii) The high $\mathrm{Li}^{+}$diffusion coefficient of $\mathrm{Co}_{2} \mathrm{VO}_{4}$ can facilitate fast electrochemical reactions, and the porous nanodisk structural design can reduce the electron and ion diffusion length, further enhancing the electrochemical kinetics; (iii) Numerous internal pores of PCVO ND and uniform nanoscale pore size buffer the volume change, and the close contact between electrode and electrolyte by PCVO ND' large specific surface area stabilize the SEI film, leading to superior long-term cycling stability of PCVO ND at a high rate.

To further investigate PCVO ND's stability, the morphologies of PCVO ND before and after 1000 cycles were examined. Figure S6a-d showed the SEM images of the PCVO ND electrode before and after 1000 cycles at $10 \mathrm{C}$. The PCVO ND exhibits a high structural stability and still maintains a hexagonal structure after 1000 cycles (Fig. S6c, d), confirming the excellent long-term cycle stability of PCVO ND. The structure of the PCVO ND after 1000 cycles was also investigated to conform the stability of PCVO ND. The XRD pattern of PCVO ND after 1000 cycles at $10 \mathrm{C}$ is shown in Fig. S6e. Compared to the pristine PCVO ND, the peaks of $\mathrm{Co}_{2} \mathrm{VO}_{4}$ were absent in the electrode after 1000 cycles. Meanwhile, two new peaks at $44.3^{\circ}$ and $65.7^{\circ}$ corresponded to the (015) and (110) diffraction planes of $\mathrm{LiVO}_{2}$, respectively [17]. The HRTEM image of PCVO ND after 1000 cycles at $10 \mathrm{C}$ (Fig. S6f) confirmed the exist of $\mathrm{LiVO}_{2}$ (lattice spacing of $0.201 \mathrm{~nm}$ ). And the lattice spacing of $0.151 \mathrm{~nm}$ corresponded to the (220) of $\mathrm{CoO}$ [17]. The XRD and HRTEM results demonstrated that PCVO ND still followed the reaction mechanism: $\mathrm{CoO}+\mathrm{Li}_{x} \mathrm{VO}_{2}+(\mathrm{y}+2)$ $\mathrm{Li}^{+}+(\mathrm{y}+2) \mathrm{e}^{-} \longleftrightarrow \mathrm{Co}+\mathrm{Li}_{2} \mathrm{O}+\mathrm{Li}_{\mathrm{x}+\mathrm{y}} \mathrm{VO}_{2}$ after 1000 cycles, further confirming the stability of PCVO ND cycled at a high rate.

To get deep insight into the excellent lithium storage kinetics of PCVO ND, CV measurements were carried at different scan rates ranging from 0.2 to $1.0 \mathrm{mV} \mathrm{s}^{-1}$ (Fig. 4f). 
The shapes of the characteristic peaks were similar with increasing scan rates. The kinetics of charge storage mechanism could be analyzed by the relationship between current (i) and scan rate $(v)$ which can be described by the following equation:

$i=a v^{b}$

In this equation, $\mathrm{a}$ and $\mathrm{b}$ are adjustable parameters. The value of $b$ ranges from 0.5 to 1.0 (0.5 for a diffusion-controlled charge storage mechanism and 1.0 for a capacitive charge storage mechanism [40]. The values of $\mathrm{b}$ can be calculated by the fitting the $\log (i)$ versus $\log (v)$. As shown in Fig. $4 \mathrm{~g}$, the values of $\mathrm{b}$ were calculated to be $0.89,0.79$, 0.91 , and 0.94 for peaks $1,2,3$, and 4 , respectively. The values of $b$ were in the range of $0.8-1.0$, suggesting a high pseudocapacitive contribution of lithium storage in PCVO ND electrode. This was further confirmed by quantifying the capacitive $\left(\mathrm{k}_{1} v\right)$ and diffusion-controlled storage contribution $\left(\mathrm{k}_{2} v^{1 / 2}\right)$ using the following formula:

$i=k_{1} v+k_{2} v^{1 / 2}$

$i / v^{1 / 2}=k_{1} v^{1 / 2}+k_{2}$

As shown in Fig. S7, a 77.0\% contribution was obtained from capacitive charge storage when scan rate was $0.6 \mathrm{mV} \mathrm{s}^{-1}$. A summary of these contributions by both components was plotted at different scan rate (Fig. 4h). The capacitive contribution increased from $69.5 \%$ to $83.7 \%$ with scan rate increasing. PCVO ND involves a pseudocapacitive charge storage mechanism concluded from above analysis. The high pseudocapacitive storage contribution might originate from porous structure of electrode, which contributed to increase surface area and enhance charge transfer kinetics.

\subsection{Comparison with Commercial Anode Materials}

In order to evaluate the practical application, the electrochemical performances of PCVO ND were compared with that of anodes in commercial LIBs. Figure 5a shows the cycling performance of PCVO ND, graphite, $\mathrm{Si}$, and $\mathrm{Li}_{4} \mathrm{Ti}_{5} \mathrm{O}_{12}$ at $400 \mathrm{~mA} \mathrm{~g}^{-1}$. It can be seen that the initial capacities of PCVO ND, graphite and $\mathrm{Li}_{4} \mathrm{Ti}_{5} \mathrm{O}_{12}$ were 1226.9, 245.5, and $91.9 \mathrm{mAh} \mathrm{g}^{-1}$ while they were 817.9, 262.7, and $79.4 \mathrm{mAh} \mathrm{g}^{-1}$ after 100 cycles. Their cycling performances were excellent, except $\mathrm{Si}$ showed a fast capacity decay (1819.7 to $27.2 \mathrm{mAh} \mathrm{g}^{-1}$ ). Thus, Si anode was not further studied in this paper. Figure $5 \mathrm{~b}$ shows the potential versus capacity plots of PCVO ND, graphite and $\mathrm{Li}_{4} \mathrm{Ti}_{5} \mathrm{O}_{12}$ at $400 \mathrm{~mA} \mathrm{~g}^{-1}$. $\mathrm{Li}_{4} \mathrm{Ti}_{5} \mathrm{O}_{12}$ displayed the lowest discharge capacity of $164.1 \mathrm{mAh} \mathrm{g}^{-1}$ and intercalated $\mathrm{Li}^{+}$at the highest potential $\left(\sim 1.55 \mathrm{~V}\right.$ vs. $\left.\mathrm{Li}^{+} / \mathrm{Li}\right)$. Such low capacity, along with high operation voltage, sacrificed the cell voltage and cell energy seriously. In contrast, PCVO ND showed the highest discharge capacity of $910.9 \mathrm{mAh} \mathrm{g}^{-1}$. And the insertion of $\mathrm{Li}^{+}$into PCVO ND occurred at a lower potential $\left(\sim 0.65 \mathrm{~V}\right.$ vs. $\left.\mathrm{Li}^{+} / \mathrm{Li}\right)$. The energy density formula in Fig. $5 \mathrm{c}$ is defined as:

$E=\frac{C n * V n}{C 1 * \mathrm{~V} 1}$

where the $E$ is the energy density relative to the LTO anode, $C_{n}$ is the specific capacity of different anodes, $V_{n}$ is the voltage difference between discharge platform and commercial $4 \mathrm{~V}$ cathode materials $(n=1,2,3,1$ means to LTO, 2 means to graphite, 3 means to CVO) [41].

The estimated energy density of PCVO ND (regarding both potential and capacity) was 15 orders of magnitude higher than that of $\mathrm{Li}_{4} \mathrm{Ti}_{5} \mathrm{O}_{12}$ if the two are coupled with a typical $4 \mathrm{~V}$ cathode (Fig. $5 \mathrm{c}$ ). Thus, $\mathrm{Li}_{4} \mathrm{Ti}_{5} \mathrm{O}_{12}$ is not suitable in high-energy-density fast-charging LIBs.

For graphite, it intercalated $\mathrm{Li}^{+}$at the lowest voltage $\left(\sim 0.1 \mathrm{~V}\right.$ vs. $\left.\mathrm{Li}^{+} / \mathrm{Li}\right)$ close to that of the Li-plating, which resulted in a safety risk due to high surface Li-plating (Li dendrite, a potential cause of short circuits). In order to compare the PCVO ND's safety with graphite at high rates, the PCVO ND and graphite anodes were charged and discharged at $4000 \mathrm{~mA} \mathrm{~g}^{-1}$ for 1000 cycles. Both PCVO ND and graphite anodes showed high cycling stability (Figs. 5d and S8). Nevertheless, PCVO ND anode displayed a high average capacity of $579.2 \mathrm{mAh} \mathrm{g}^{-1}$, while graphite anode showed an average capacity of only 12.1 $\mathrm{mAh} \mathrm{g}^{-1}$ (Fig. 5d). SEM images of PCVO ND and graphite anodes before and after 1000 cycles are shown in Fig. 5e-j. There were no visible Li dendrites in PCVO ND electrode after 1000 cycles (Fig. 5f, g). Li dendrites (with a wire-like shape) were clearly found in graphite electrodes (Fig. 5i, j). Besides, the EIS of PCVO ND electrode cycled at $4000 \mathrm{~mA} \mathrm{~g}^{-1}$ from before cycling to after 1000 cycles was also tested. The results are shown in Fig. S9. The impedance had minor differences between the 100th and 1000th cycles, confirming that the Li dendrites have not 

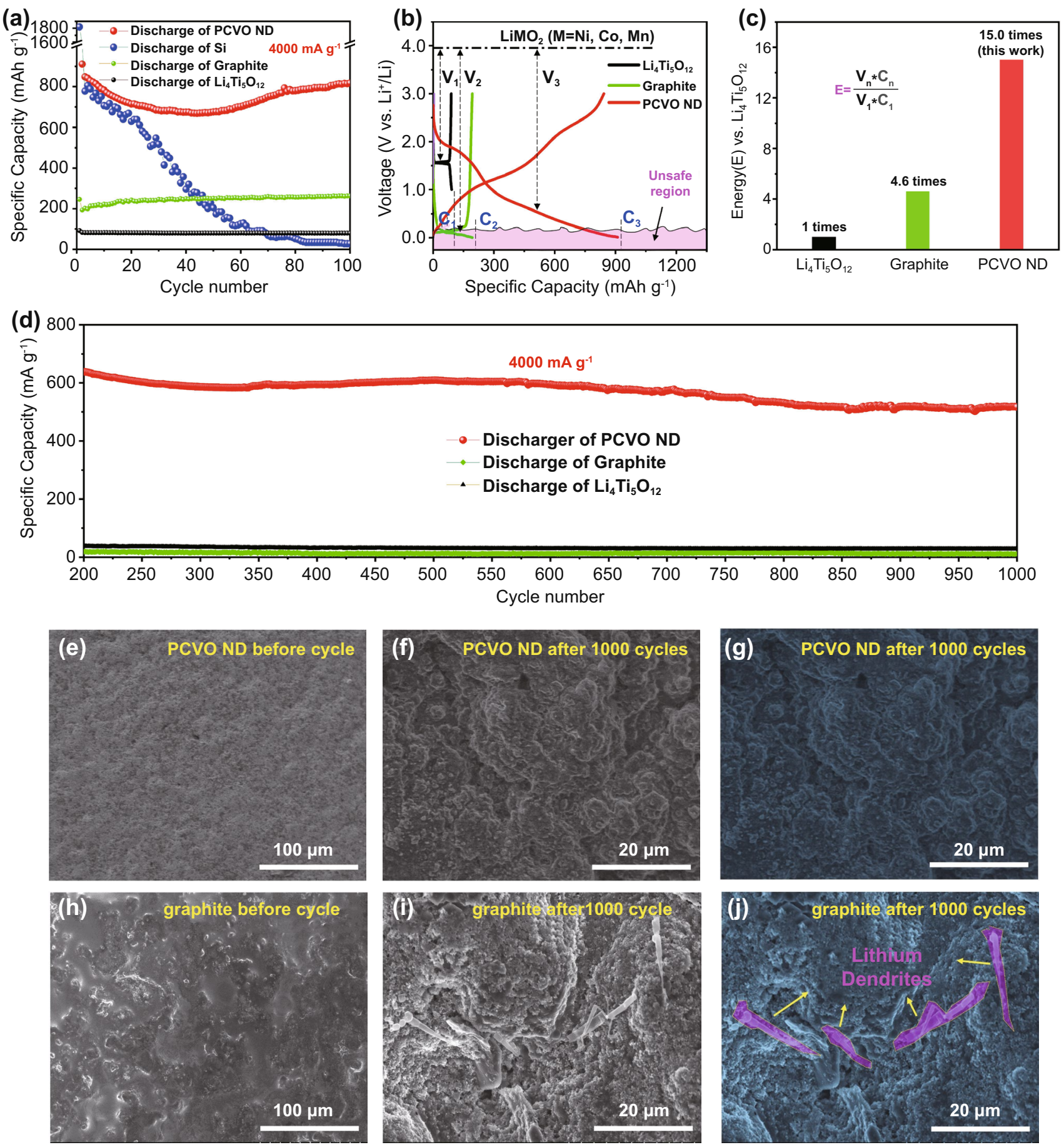

Fig. 5 a The cycling performance of PCVO ND and commercial graphite, $\mathrm{Si}$ and $\mathrm{Li}_{4} \mathrm{Ti}_{5} \mathrm{O}_{12}$ anode materials at $400 \mathrm{~mA} \mathrm{~g}^{-1}$. b The potential versus capacity plots of PCVO ND, commercial graphite, and $\mathrm{Li}_{4} \mathrm{Ti}_{5} \mathrm{O}_{12}$ at $400 \mathrm{~mA} \mathrm{~g}{ }^{-1}$. c The energy density comparison of PCVO ND, commercial graphite, and $\mathrm{Li}_{4} \mathrm{Ti}_{5} \mathrm{O}_{12}$. $\mathbf{d}$ The long-term cycling performance of PCVO ND, $\mathrm{Li}_{4} \mathrm{Ti}_{5} \mathrm{O}_{12}$, and graphite at $4000 \mathrm{~mA} \mathrm{~g}^{-1}$ from the 200th to 1000th cycle. e SEM image of PCVO ND electrode before cycling. $\mathbf{f}$ and $\mathbf{g}$ SEM images of PCVO ND electrode after 1000 cycles at $4000 \mathrm{~mA} \mathrm{~g}^{-1}$. h SEM image of graphite electrode before cycling. $\mathbf{i}$ and $\mathbf{j}$ SEM images of graphite electrode after 1000 cycles at $4000 \mathrm{~mA} \mathrm{~g}^{-1}$ 
(a)

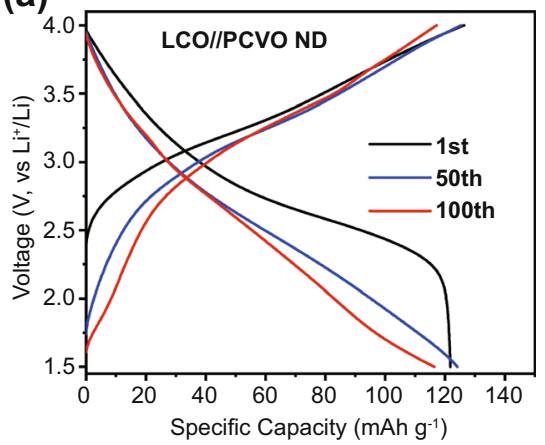

(b)

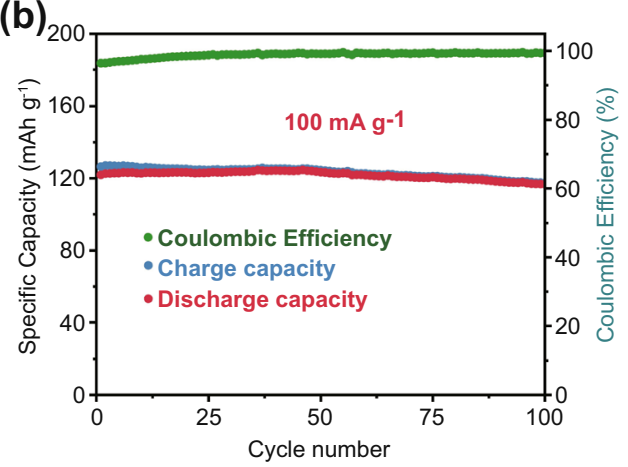

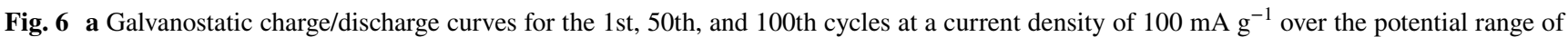
1.5-4.0 V. b Cycling performance of the $\mathrm{LiCoO}_{2} / / \mathrm{PCVO} \mathrm{ND}$ full cell at a current density of $100 \mathrm{~mA} \mathrm{~g}^{-1}$

been formed after 1000 cycles. These results confirmed the commercial feasibility of PCVO ND in safe, fast-charging, high-energy-density LIBs.

\subsection{Full Cell Performance of PCVO ND}

According to the outstanding performance of the Li// PCVO ND half cells, we investigated the full cell performance using PCVO ND as anode and commercial $\mathrm{LiCoO}_{2}$ materials as the cathode. According to the principle of capacity balance, the mass ratio of PCVO ND to $\mathrm{LiCoO}_{2}$ was controlled to be about 1: 6 . The half-cell battery with the active material was pre-activated to form a stable SEI layer and then taken out to fabricate the full cell. Figure $6 \mathrm{a}$ presents the full cell voltage profiles after the 1st, 50th, and 100th cycles at the voltage window of $1.5-4.0 \mathrm{~V}$ at $100 \mathrm{~mA} \mathrm{~g}^{-1}$. The initial charge and discharge capacities are 126.4 and $121.8 \mathrm{mAh} \mathrm{g}^{-1}$, respectively, exhibiting a high coulombic efficiency of $96.3 \%$. Besides, the cycling performance of lithium-ion full cell is shown in Fig. $6 \mathrm{~b}$. The full cell exhibits a good discharge capacity of 116.4 $\mathrm{mAh} \mathrm{g}^{-1}$ after 100 cycles with a capacity retention of 95.5\%. From these results, it is evident that the $\mathrm{LiCoO}_{2} / /$ PCVO ND full cell exhibits outstanding performance in terms of reversible capacity, stable cycling behavior and high coulombic efficiency, confirming the potential of the PCVO ND as an anode material for LIBs.

\section{Conclusions}

Our studies showed that $\mathrm{Co}_{2} \mathrm{VO}_{4}$ was a promising anode material for high-energy-density fast-charging LIBs due to its high capacity $\left(\sim 1000 \mathrm{mAh} \mathrm{g}^{-1}\right)$, safe lithiation potential $\left(\sim 0.65 \mathrm{~V}\right.$ vs. $\left.\mathrm{Li}^{+} / \mathrm{Li}\right)$, high $\mathrm{Li}^{+}$diffusion coefficient $\left(6.95 \times 10^{-10} \mathrm{~cm}^{2} \mathrm{~s}^{-1}\right)$, and high cycling stability. In order to further enhance $\mathrm{Li}^{+}$and electrons transfer, we designed a hexagonal porous $\mathrm{Co}_{2} \mathrm{VO}_{4}$ nanodisk (PCVO ND) structure, which features a high specific surface area of $74.57 \mathrm{~m}^{2} \mathrm{~g}^{-1}$ and numerous pores with a uniform pore size of $14 \mathrm{~nm}$ in PCVO ND. The porous nanodisk structural design can reduce the electron and ion diffusion length at the electrode level, further enhancing the electrochemical kinetics. Moreover, the close contact between electrode and electrolyte by the large specific surface area of PCVO ND stabilizes the SEI film, leading to superior fast-charging performance of PCVO ND. As a result, the PCVO ND showed a high initial reversible capacity of $911.0 \mathrm{mAh} \mathrm{g}^{-1}$ at $0.4 \mathrm{C}$, excellent fast-charging capacity (average capacity of $579.2 \mathrm{mAh} \mathrm{g}^{-1}$ at $4 \mathrm{C}$ and $344.3 \mathrm{mAh} \mathrm{g}^{-1}$ at $10 \mathrm{C}$ for 1000 cycles), outstanding long-term cycling stability (only $0.024 \%$ capacity loss per cycle at $10 \mathrm{C}$ for 1000 cycles). Due to its superior fastcharging performance and simple preparation, the PCVO ND has high commercial feasibility in high-energy-density fast-charging LIBs.

Acknowledgements This work was supported by the National Key Research and Development Project (2018YFE0124800) and 
the National Nature Science Foundation of China (51702157, 51873086, 51673096).

Funding Open access funding provided by Shanghai Jiao Tong University.

Open Access This article is licensed under a Creative Commons Attribution 4.0 International License, which permits use, sharing, adaptation, distribution and reproduction in any medium or format, as long as you give appropriate credit to the original author(s) and the source, provide a link to the Creative Commons licence, and indicate if changes were made. The images or other third party material in this article are included in the article's Creative Commons licence, unless indicated otherwise in a credit line to the material. If material is not included in the article's Creative Commons licence and your intended use is not permitted by statutory regulation or exceeds the permitted use, you will need to obtain permission directly from the copyright holder. To view a copy of this licence, visit http://creativecommons.org/licenses/by/4.0/.

Supplementary Information The online version contains supplementary material available at https://doi.org/10.1007/ s40820-021-00758-5.

\section{References}

1. G. Harper, R. Sommerville, E. Kendrick, L. Driscoll, P. Slater et al., Recycling lithium-ion batteries from electric vehicles. Nature 575, 75-86 (2019). https://doi.org/10.1038/ s41586-019-1682-5

2. Y. Cao, K. Geng, H. Geng, H. Ang, J. Pei et al., Metal-oleate complex-derived bimetallic oxides nanoparticles encapsulated in 3D graphene networks as anodes for efficient lithium storage with pseudocapacitance. Nano-Micro Lett. 11, 15 (2019). https://doi.org/10.1007/s40820-019-0247-3

3. F. Liao, E. Molin, B. van Wee, Consumer preferences for electric vehicles: a literature review. Transp. Rev. 37, 252275 (2016). https://doi.org/10.1080/01441647.2016.12307 94

4. A. Tomaszewska, Z. Chu, X. Feng, S. O'Kane, X. Liu et al., Lithium-ion battery fast charging: a review. eTransportation 1, 100011 (2019). https://doi.org/10.1016/j.etran.2019.100011

5. A. Masias, J. Marcicki, W.A. Paxton, Opportunities and challenges of lithium ion batteries in automotive applications. ACS Energy. Lett. 6, 621-630 (2021). https://doi.org/10.1021/acsen ergylett.0c02584

6. E.J. Berg, C. Villevieille, D. Streich, S. Trabesinger, P. Novák, Rechargeable batteries: grasping for the limits of chemistry. J. Electrochem. Soc. 162, A2468-A2475 (2015). https://doi.org/ 10.1149/2.0081514jes

7. Y.X. Yao, C. Yan, Q. Zhang, Emerging interfacial chemistry of graphite anodes in lithium-ion batteries. Chem. Commun. 56, 14570-14584 (2020). https://doi.org/10.1039/d0cc05084a
8. L. Wang, J. Han, D. Kong, Y. Tao, Q. Yang, Enhanced roles of carbon architectures in high-performance lithium-ion batteries. Nano-Micro Lett. 11, 5 (2019). https://doi.org/10.1007/ s40820-018-0233-1

9. X. Liu, L. Yin, D. Ren, L. Wang, Y. Ren et al., In situ observation of thermal-driven degradation and safety concerns of lithiated graphite anode. Nat. Commun. 12, 4235 (2021). https://doi.org/10.1038/s41467-021-24404-1

10. D. Wang, H. Liu, Z. Shan, D. Xia, R. Na et al., Nitrogen, sulfur co-doped porous graphene boosting $\mathrm{Li}_{4} \mathrm{Ti}_{5} \mathrm{O}_{12}$ anode performance for high-rate and long-life lithium ion batteries. Energy. Storage. Mater. 27, 387-395 (2020). https://doi.org/ 10.1016/j.ensm.2020.02.019

11. J. Liu, A. Wei, G. Pan, S. Shen, Z. Xiao et al., Self-supported hierarchical porous $\mathrm{Li}_{4} \mathrm{Ti}_{5} \mathrm{O}_{12} /$ carbon arrays for boosted lithium ion storage. J. Energy Chem. 54, 754-760 (2021). https:// doi.org/10.1016/j.jechem.2020.06.017

12. B. Gangaja, S. Nair, D. Santhanagopalan, Surface-engineered $\mathrm{Li}_{4} \mathrm{Ti}_{5} \mathrm{O}_{12}$ nano-structures for high-power li-ion batteries. Nano-Micro Lett. 12, 30 (2020). https://doi.org/10.1007/ s40820-020-0366-x

13. G. Huang, J. Han, Z. Lu, D. Wei, H. Kashani et al., Ultrastable silicon anode by three-dimensional nanoarchitecture design. ACS Nano 14, 4374-4382 (2020). https://doi.org/10.1021/ acsnano.9b09928

14. X. Liu, Z. Xu, A. Iqbal, M. Chen, N. Ali et al., Chemical coupled PEDOT:PSS/Si electrode: suppressed electrolyte consumption enables long-term stability. Nano-Micro Lett. 13, 54 (2021). https://doi.org/10.1007/s40820-020-00564-5

15. Z. Xiao, C. Lei, C. Yu, X. Chen, Z.Zhu et al., Si@ $\mathrm{Si}_{3} \mathrm{~N}_{4} @ \mathrm{C}$ composite with egg-like structure as high-performance anode material for lithium ion batteries. Energy Storage Mater. 24, 565-573 (2020). https://doi.org/10.1016/j.ensm.2019.06.031

16. J. Liu, P. Zhang, D. Yu, K. Li, J. Wu et al., Hierarchical $\mathrm{Co}_{2} \mathrm{VO}_{4}$ yolk-shell microspheres confined by $\mathrm{N}$-doped carbon layer as anode for high-rate lithium-ion batteries. J. Electroanal. Chem. 882, 115027 (2021). https://doi.org/10.1016/j.jelec hem.2021.115027

17. C. Zhu, Z. Liu, J. Wang, J. Pu, W. Wu et al., Novel $\mathrm{Co}_{2} \mathrm{VO}_{4}$ anodes using ultralight $3 \mathrm{~d}$ metallic current collector and carbon sandwiched structures for high-performance li-ion batteries. Small 13, 171260 (2017). https://doi.org/10.1002/smll. 201701260

18. G. Kresse, J. Hafner, Ab initio molecular dynamics for liquid metals. Phys. Rev. B 47, 558-561 (1993). https://doi.org/10. 1103/PhysRevB.47.558

19. G. Kresse, J. Furthmuller, J. Hafner, Theory of the crystal structures of selenium and tellurium: the effect of generalizedgradient corrections to the local-density approximation. Phys. Rev. B 50, 13181-13185 (1994). https://doi.org/10.1103/ PhysRevB.50.13181

20. G. Kresse, J. Furthmuller, Efficiency of ab-initio total energy calculations for metals and semiconductors using a plane-wave basis set. Phys. Rev. B 6, 15-50 (1996). https://doi.org/10. 1016/0927-0256(96)00008-0 
21. P.E. Blochl, Projector augmented-wave method. Phys. Rev. B 50, 17953-17979 (1994). https://doi.org/10.1103/PhysRevB. 50.17953

22. J.P. Perdew, K. Burke, M. Ernzerhof, Generalized gradient approximation made simple. Phys. Rev. Lett. 78, 1396 (1996). https://doi.org/10.1103/PhysRevLett.77.3865

23. S.L. Dudarev, G.A. Botton, S.Y. Savrasov, C.J. Humphreys, A.P. Sutton, Electron-energy-loss spectra and the structural stability of nickel oxide: an LSDA1U study. Phys. Rev. B 57, 1505-1509 (1998). https://doi.org/10.1103/PhysRevB.57.1505

24. S. Nosé, A unified formulation of the constant temperature molecular dynamics methods. J. Chem. Phys. 81, 511-519 (1984). https://doi.org/10.1063/1.447334

25. F. Wu, C. Yu, W. Liu, T. Wang, J. Feng et al., Large-scale synthesis of $\mathrm{Co}_{2} \mathrm{~V}_{2} \mathrm{O}_{7}$ hexagonal microplatelets under ambient conditions for highly reversible lithium storage. J. Mater. Chem. A 3, 16728-16736 (2015). https://doi.org/10.1039/ c5ta03106k

26. W. Cai, C. Yan, Y.-X. Yao, L. Xu, R. Xu et al., Rapid lithium diffusion in order@ disorder pathways for fast-charging graphite anodes. Small Structures 1, 2000010 (2020). https://doi. org/10.1002/sstr.202000010

27. C. Lin, B. Ding, Y. Xin, F. Cheng, M.O. Lai et al., Advanced electrochemical performance of $\mathrm{Li}_{4} \mathrm{Ti}_{5} \mathrm{O}_{12}$-based materials for lithium-ion battery: synergistic effect of doping and compositing. J. Power Sources 248, 1034-1041 (2014). https://doi.org/ 10.1016/j.jpowsour.2013.09.120

28. S.R. Sahu, V.R. Rikka, P. Haridoss, A. Chatterjee, R. Gopalan et al., A novel $\alpha-\mathrm{MoO}_{3} /$ single-walled carbon nanohorns composite as high-performance anode material for fast-charging lithium-ion battery. Adv. Energy Mater. 10, 2001627 (2020). https://doi.org/10.1002/aenm.202001627

29. R. Tao, G. Yang, E.C. Self, J. Liang, J.R. Dunlap et al., Ionic liquid-directed nanoporous $\mathrm{TiNb}_{2} \mathrm{O}_{7}$ anodes with superior performance for fast-rechargeable lithium-ion batteries. Small 16, e2001884 (2020). https://doi.org/10.1002/smll.202001884

30. Q. Sun, Z. Cao, J. Zhang, H. Cheng, J. Zhang et al., Metal catalyst to construct carbon nanotubes networks on metal oxide microparticles towards designing high-performance electrode for high-voltage lithium-ion batteries. Adv. Funct. Mater. 31, 2009122 (2021). https://doi.org/10.1002/adfm.202009122

31. H. Li, L. Jiang, Q. Feng, Z. Huang, H. Zhou et al., Ultra-fast transfer and high storage of $\mathrm{Li}^{+} / \mathrm{Na}^{+}$in $\mathrm{MnO}$ quantum dots@ carbon hetero-nanotubes: appropriate quantum dots to improve the rate. Energy Storage Mater. 17, 157-166 (2019). https:// doi.org/10.1016/j.ensm.2018.07.021

32. S. Chen, H. Duan, L. Zhao, Y. Zhao, A. Gupta et al., Electrochemical performance and $\mathrm{Li}^{+}$insertion/extraction mechanism of carbon-coated cerium metavanadate as a novel anode for lithium-ion batteries. J. Power Sources 413, 250-258 (2019). https://doi.org/10.1016/j.jpowsour.2018.12.053

33. C. Mu, J. Mao, J. Guo, Q. Guo, Z. Li et al., Rational design of spinel cobalt vanadate oxide $\mathrm{Co}_{2} \mathrm{VO}_{4}$ for superior electrocatalysis. Adv. Mater. 32, e1907168 (2020). https://doi.org/10. 1002/adma.201907168

34. D. Su, L. Liu, Z. Liu, J. Liu, M. Yang et al., Wire-in-wire $\mathrm{TiO}_{2} / \mathrm{C}$ nanofibers free-standing anodes for $\mathrm{Li}$-ion and $\mathrm{K}$-ion batteries with long cycling stability and high capacity. Nano-Micro Lett. 13, 107 (2021). https://doi.org/10.1007/ s40820-021-00632-4

35. Y. Xiao, C. Tian, M. Tian, A. Wu, H. Yan et al., Cobalt-vanadium bimetal-based nanoplates for efficient overall water splitting. Sci. China Mater. 61, 80-90 (2017). https://doi.org/10. 1007/s40843-017-9113-1

36. Q. Zong, W. Du, C. Liu, H. Yang, Q. Zhang et al., Enhanced reversible zinc ion intercalation in deficient ammonium vanadate for high-performance aqueous zinc-ion battery. Nano-Micro Lett. 13, 116 (2021). https://doi.org/10.1007/ s40820-021-00641-3

37. B. He, J. Wang, Y. Fan, Y. Jiang, Y. Zhai et al., Mesoporous $\mathrm{CoO} / \mathrm{Co}-\mathrm{N}-\mathrm{C}$ nanofibers as efficient cathode catalysts for $\mathrm{Li}-\mathrm{O}_{2}$ batteries. J. Mater. Chem. A 6, 19075-19084 (2018). https://doi.org/10.1039/c8ta07185c

38. L. Zhang, K. Zhao, Y. Luo, Y. Dong, W. Xu et al., Acetylene black induced heterogeneous growth of macroporous $\mathrm{CoV}_{2} \mathrm{O}_{6}$ nanosheet for high-rate pseudo-capacitive lithium-ion battery anode. ACS Appl. Mater. Inter. 8, 7139-7146 (2016). https:// doi.org/10.1021/acsami.6b00596

39. J.S. Lu, I.V.B. Maggay, W.R. Liu, $\mathrm{CoV}_{2} \mathrm{O}_{4}$ : a novel anode material for lithium-ion batteries with excellent electrochemical performance. Chem. Commun. 54, 3094-3097 (2018). https://doi.org/10.1039/c7cc09762j

40. J. Chen, Y. Luo, W. Zhang, Y. Qiao, X. Cao et al., Tuning interface bridging between $\mathrm{MoSe}_{2}$ and three-dimensional carbon framework by incorporation of mocintermediate to boost lithium storage capability. Nano-Micro Lett. 12, 171 (2020). https://doi.org/10.1007/s40820-020-00511-4

41. H. Li, X. Liu, T. Zhai, D. Li, H. Zhou, $\mathrm{Li}_{3} \mathrm{VO}_{4}$ : a promising insertion anode material for lithium-ion batteries. Adv. Energy Mater. 3, 428-432 (2013). https://doi.org/10.1002/aenm.20120 0833

42. S. Lu, T. Zhu, Z. Li, Y. Pang, L. Shi et al., Ordered mesoporous carbon supported $\mathrm{Ni}_{3} \mathrm{~V}_{2} \mathrm{O}_{8}$ composites for lithium-ion batteries with long-term and high-rate performance. J. Mater. Chem. A 6, 7005-7013 (2018). https://doi.org/10.1039/C7TA11268H 